\title{
Immunohistochemical Detection of Proteins Associated with Multidrug Resistance to Anti-Cancer Drugs in Canine and Feline Primary Pulmonary Carcinoma
}

\author{
Tatsuro HIFUMI ${ }^{1)}$, Noriaki MIYOSHI ${ }^{1) *}$, Hiroaki KAWAGUCHI'), Kohji NOMURA ${ }^{3)}$ and Nobuhiro YASUDA ${ }^{1)}$ \\ ${ }^{1)}$ Departments of Veterinary Pathology and ${ }^{2)}$ Veterinary Experimental Animal Science, Faculty of Agriculture, Kagoshima University, \\ Kagoshima 890-0065 and ${ }^{3)}$ Marupi Lifetech Co., Ltd., 103 Fushio-cho, Ikeda, Osaka 563-8691, Japan
}

(Received 17 November 2009/Accepted 31 December 2009/Published online in J-STAGE 20 January 2010)

ABSTRACT. Fifty-two canine and eighteen feline primary pulmonary carcinomas were evaluated immunohistochemically for the expression of proteins associated with multidrug resistance to anti-cancer drugs. P-glycoprotein (PGP), multidrug resistance-related protein (MRP) and lung resistance-related protein (LRP) expression were frequently observed in neoplastic cells of all carcinoma types, and metallothionein (MT) expression was observed in about half of each carcinoma type. Furthermore, overlapping expression was detected in all positive cases. These results indicate that most canine and feline primary pulmonary carcinomas may have strong multidrug resistance, which is related to the PGP, MRP, LRP or MT expression. It might be difficult to treat canine and feline primary pulmonary carcinomas using anti-cancer drugs because of multidrug resistance.

KEY WORDS: immunohistochemistry, lung resistance-related protein, metallothionein, multidrug resistance-related protein, P-glycoprotein.

J. Vet. Med. Sci. 72(5): 665-668, 2010

Human primary pulmonary carcinoma is divided into 2 groups; small cell lung carcinoma (SCLC) and non-small cell lung carcinoma (NSCLC). Surgical resection is not suitable for SCLC because of metastasis at the time of diagnosis in many cases; therefore, chemotherapy is recommended generally. For NSCLC, however, including adenocarcinoma, adenosquamous carcinoma and squamous cell carcinoma, chemotherapy is less effective; therefore, surgical resection is recommended generally [12]. Primary pulmonary tumors in domestic animals are uncommon to extremely rare, with a prevalence of $0.1-0.9 \%$ in dogs, a little higher than in cats [23]. In the treatment of canine and feline primary pulmonary carcinoma, surgical resection is recommended [18], but to reduce the risk of local recurrence and metastasis, adjuvant chemotherapy is required similarly to the treatment for human NSCLC.

P-glycoprotein (PGP), a 150-170 kDa plasma membrane protein, belongs to the ATP binding cassette (ABC) superfamily of transporter proteins, and can extrude a range of hydrophobic anti-cancer drugs from the cell [20]. Overexpression of PGP is associated with resistance to different types of anti-cancer drugs (e.g. daunorubicin, doxorubicin, mitoxantrone, etoposide, teniposide, vinblastine, vincristine, mitomycin C, paclitaxel, actinomycin D and topotecan) [6]. Multidrug resistance-related protein (MRP), which belongs to the ABC superfamily as PGP, is a $190 \mathrm{kDa}$ membrane-bound glycoprotein. MRP probably works by direct extrusion of cytotoxic drugs from the cell and/or by mediating sequestration of the drugs into intracellular compartments, both leading to a reduction in effective intracellular drug concentrations [16]. Overexpression of MRP is associated with resistance to doxorubicin, vincristine, actinomycin

\footnotetext{
* Correspondence to: Miyoshi, N., Department of Veterinary Pathology, Faculty of Agriculture, Kagoshima University, 1-2124, Korimoto, Kagoshima 890-0065, Japan.

e-mail: miyoshi@agri.kagoshima-u.ac.jp
}

D, etoposide and colchicine [7, 22]. Lung resistance-related protein (LRP) is a $110 \mathrm{kDa}$ protein found in multidrug-resistant cell lines not expressing PGP. LRP is the main component of vault protein, and plays a role in drug resistance by regulating the nucleocytoplasmic transport of drugs [8]. The expression of LRP is involved in resistance to doxorubicin, vincristine, etoposide, paclitaxel, and gramicidinD [10]. In one previous report, there was no relationship between the mRNA expression level of LRP and the phenotype of adriamycin resistance in feline lymphoma cell line [5]. Metallothionein (MT) is a low molecular weight protein $(10 \mathrm{kDa})$ with a high cysteine content $(30 \%)$, exhibiting selective binding affinity for $\mathrm{Zn}, \mathrm{Cu}$ and other group II heavy metals. MT is thought to play essential roles in $\mathrm{Zn}$ and $\mathrm{Cu}$ metabolism, heavy metal transport (particularly in copper-loaded animals), and to protect cells from oxidative stress [2]. According to previous reports, in dogs, MT immunoreactivity was observed in the central nervous system, liver, kidney etc., and MT cDNA obtained from the liver of a cadmium-treated beagle was cloned and sequenced $[11,21]$. MT expression increases following chemotherapy and may confer resistance in lung cancer, especially NSCLC [14]. Tumor cell lines with acquired resistance to cisplatin overexpressed MT [9]. MT expression has been associated with poor prognosis in a variety of tumors [4].

In dogs and cats, there are reports of the immunohistochemical study of the expression of proteins associated with multidrug resistance in mast cell tumor, mammary gland tumor and melanocytic tumor, but there are no reports about canine and feline primary pulmonary carcinoma [2, 15]. The aim of this study was to investigate the expression of PGP, MRP, LRP and MT using immunohistochemical methods in canine and feline primary pulmonary carcinoma, and to estimate the effectiveness to chemotherapy.

Fifty-two canine and eighteen feline primary pulmonary 
carcinoma tissue samples were obtained from private animal hospitals. All samples were fixed in $10 \%$ or $10 \%$ neutral-buffered formalin, embedded in paraffin wax and sectioned at $3 \mu \mathrm{m}$. Sections were stained with hematoxylin and eosin (HE), and classified histopathologically based on WHO classification [3]. There was no clinical information of patients after surgical resection. When some samples of the same tumor were available, only one block from each tumor was selected for immunohistochemical staining.

For immunohistochemical staining, all paraffin sections cut at $3 \mu \mathrm{m}$ were mounted on MAS-coating slides (S9215; Matsunami Glass, Ind., Ltd., Osaka, Japan). After deparaffinization and rehydration, all sections were pretreated by autoclaving for $15 \mathrm{~min}$ at $121^{\circ} \mathrm{C}$ in $0.01 \mathrm{M}$ citrate buffer solution ( $\mathrm{pH}$ 6.0), and endogenous peroxidase activity was quenched by immersion in $0.3 \%$ hydrogen peroxide diluted with methanol for $10 \mathrm{~min}$. As primary antibodies, anti-PGP monoclonal antibody (C494, 1:200; DAKO Corporation, CA, U.S.A.), anti-MRP monoclonal antibody (m6, 1:50; Nichirei, Tokyo, Japan), anti-LRP monoclonal antibody (1014, 1:50; Santa Cruz Biotechnology, Inc., CA, U.S.A.), and anti-MT monoclonal antibody (E9, 1:25; DAKO) were used. The slides were incubated with anti-MT monoclonal antibody by microwaving for $30 \mathrm{~min}$, and with anti-PGP, MRP and LRP monoclonal antibodies at $4{ }^{\circ} \mathrm{C}$ overnight. The slides were incubated with EnVision polymer reagent (DAKO) by microwaving for 6 min with the anti-MT monoclonal antibody, and were incubated for $30 \mathrm{~min}$ at room temperature with anti-PGP, MRP and LRP monoclonal antibodies. All slides were incubated for $10 \mathrm{~min}$ in a solution of $0.075 \%$ 3,3'-diaminobenzidine tetrahydrochloride (DAB) in $0.05 \mathrm{M}$ Tris- $\mathrm{HCl}(\mathrm{pH} 7.5)$ with $0.0225 \%$ hydrogen peroxide and counterstained with Mayer's hematoxylin. Normal proximal tubular epithelial cells of canine or feline kidney for anti-PGP, MRP and MT and normal bronchial epithelial cells of canine or feline lung for anti-LRP were used as positive controls. Tumor was considered to positive for the antibodies when more than $10 \%$ of the neoplastic population was positive, as reported previously [15].

The 52 canine primary pulmonary carcinomas were classified into 41 adenocarcinomas, 7 adenosquamous carcinomas, 2 squamous cell carcinomas and 2 combined carcinomas. The 18 feline primary pulmonary carcinomas were classified into 13 adenocarcinomas and 5 adenosquamous carcinomas. PGP expression was found in the cell membrane of adenocarcinoma and combined carcinoma, and in the cytoplasm of adenosquamous carcinoma and squamous cell carcinoma (Fig. 1). MRP and LRP expressions were found in the cytoplasm, and LRP expression was only located in tumor cells of the luminal structure in canine combined carcinoma (Figs. 2 and 3). MT expression was found in the cytoplasm only or both the cytoplasm and nucleus (Fig. 4). In canine primary pulmonary carcinomas, the ratio of the expressions of PGP, MRP, LRP and MT was 48/52 (92.3\%), 50/52 (96.2\%), 44/52 (84.6\%), and 25/52 $(48.1 \%)$, respectively (Table 1$)$. In feline primary pulmonary carcinomas, the ratio of the expressions of PGP, MRP,

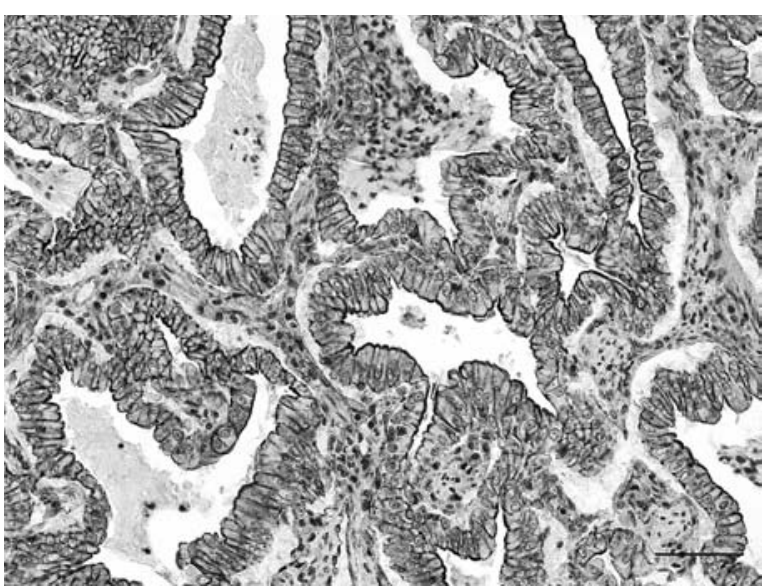

Fig. 1. Immunohistochemistry of neoplastic cells from feline adenocarcinoma using anti-PGP antibody. Neoplastic cells show a positive reaction in the cell membrane. Mayer's hematoxylin counterstaining. Bar $=50 \mu \mathrm{m}$.

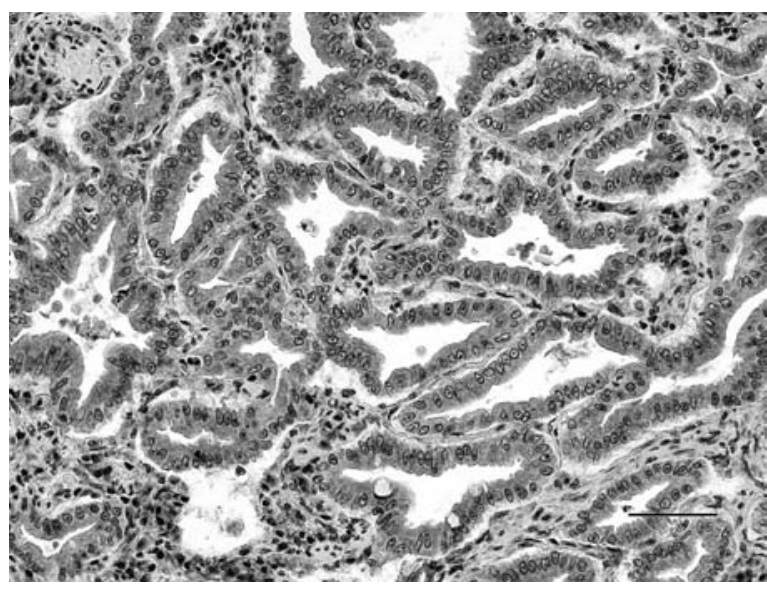

Fig. 2. Immunohistochemistry of neoplastic cells from feline adenocarcinoma using anti-MRP antibody. Neoplastic cells showing intracytoplasmic immunoreactivity. Mayer's hematoxylin counterstaining. Bar $=50 \mu \mathrm{m}$.

LRP and MT was 18/18 (100\%), 18/18 (100\%), 18/18 $(100 \%)$, and 9/18 (50.0\%), respectively (Table 2). In addition, more than two proteins were coexpressed in all positive cases. In both canine and feline primary pulmonary carcinoma, the expressions of PGP, MRP, LRP and MT were almost the same for each histopathological characteristic; thus, there was no correlation between their expression and the histopathological characteristics.

In human NSCLC, cisplatin-based chemotherapy (e.g. cisplatin and vinorelbine) is used for adjuvant chemotherapy as a standard protocol [13]. In contrast, there is no effective protocol of chemotherapy for primary pulmonary carcinoma in veterinary medicine [18]. Platinum-containing drugs, such as cisplatin and carboplatin, have been used to treat canine primary pulmonary carcinoma, but positive results were not achieved [19]. There is only one report of a 


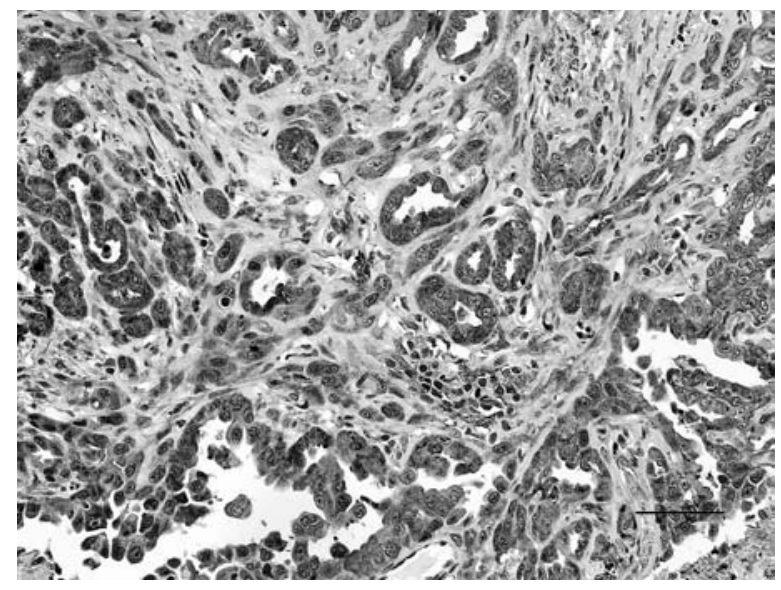

Fig. 3. Immunohistochemistry of neoplastic cells from canine adenocarcinoma using anti-LRP antibody. Neoplastic cells showing intracytoplasmic immunoreactivity. Mayer's hematoxylin counterstaining. Bar $=50 \mu \mathrm{m}$.

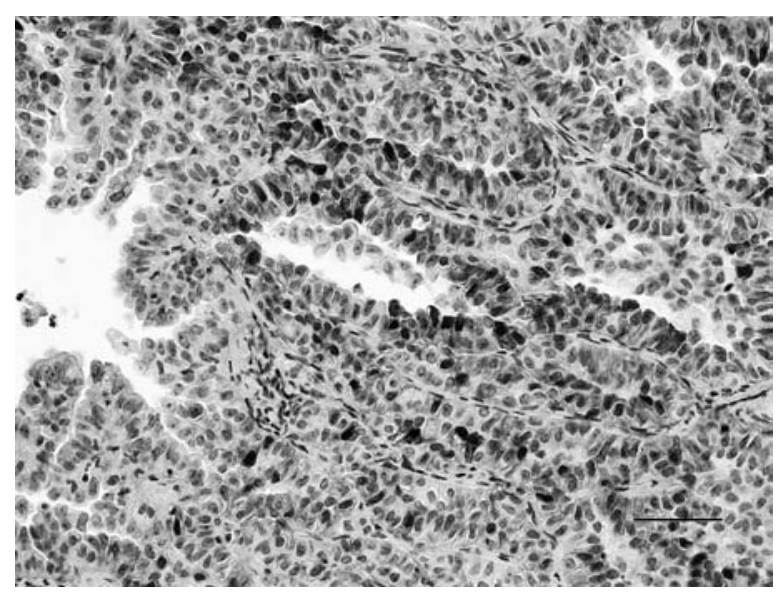

Fig. 4. Immunohistochemistry of neoplastic cells from canine adenocarcinoma using anti-MT antibody. Neoplastic cells show a positive reaction in both cell membrane and cytoplasm. Mayer's hematoxylin counterstaining. Bar $=50 \mu \mathrm{m}$. cat with well-differentiated pulmonary adenocarcinoma surviving for more than 1040 days (>115 days; overall median survival time in cat with pulmonary carcinoma) with no evidence of metastatic disease by pneumonectomy and adjuvant mitoxantrone chemotherapy [1]. Considering these previous reports, chemotherapy for canine and feline primary pulmonary carcinoma may be less effective. In human pulmonary carcinoma, there is a report on immunohistochemistry investigating the correlation between the expression of proteins associated with multidrug resistance and the response to chemotherapy, which indicated that coexpressed proteins associated with multidrug resistance seemed to have a negative impact on the response to chemotherapy [17]. As a result of this study, in both canine and feline primary pulmonary carcinomas, PGP, MRP, LRP were expressed in most cases and MT was expressed in about $50 \%$ of cases, and more than two different proteins were coexpressed in all positive cases. Therefore, this result may raise the possibility of strong multidrug resistance in canine and feline primary pulmonary carcinomas. As it was uncertain whether patients received chemotherapy before surgical resection in this study, we could not detect whether multidrug resistance is instinctive or acquired.

In conclusion, there may be strong multidrug resistance without relation to histopathological characteristics in canine and feline primary pulmonary carcinomas, which may lead to inefficient chemotherapy. Further investigation of other multidrug resistance markers (e.g. glutathione Stransferase, topoisomerase II) in canine and feline primary pulmonary carcinomas and analysis of the correlation between the expression of proteins associated with multidrug resistance and the response to chemotherapy as clinical treatment is required.

\section{REFERENCES}

1. Clements, D.N., Hogan, A.M. and Cave, T.A. 2004. Treatment of a well differentiated pulmonary adenocarcinoma in a cat by pneumonectomy and adjuvant mitoxantrone chemotherapy. $J$. Feline Med. Surg. 6: 199-205.

2. Dincer, Z., Jasani, B., Haywood, S., Mullins, J.E. and Fuent-

Table 1. Expression of proteins associated with multidrug resistance to anti-cancer drugs in canine primary pulmonary carcinomas

\begin{tabular}{cccccc}
\hline Protein & Overall $[\mathrm{n}=52](\%)$ & Adenocarcinoma [n=42] (\%) & Adenosqamous carcinoma [n=7] (\%) & Squamous cell carcinoma [n=2] (\%) & Combined carcinoma [n=2] (\%) \\
\hline PGP & $48(92.3)$ & $38(92.3)$ & $6(85.7)$ & $2(100)$ & $2(100)$ \\
MRP & $50(96.2)$ & $39(95.1)$ & $7(100)$ & $2(100)$ & $2(100)$ \\
LRP & $44(84.6)$ & $34(82.9)$ & $7(100)$ & $2(100)$ & $1(50.0)$ \\
MT & $25(48.1)$ & $18(43.9)$ & $5(71.4)$ & $1(50.0)$ & $1(50.0)$ \\
\hline
\end{tabular}

Table 2. Expression of proteins associated with multidrug resistance to anti-cancer drugs in feline primary pulmonary carcinomas

\begin{tabular}{cccc}
\hline Protein & Overall $[\mathrm{n}=18](\%)$ & Adenocarcinoma $[\mathrm{n}=13](\%)$ & Adenosqamous carcinoma $[\mathrm{n}=5](\%)$ \\
\hline PGP & $18(100)$ & $13(100)$ & $5(100)$ \\
MRP & $18(100)$ & $13(100)$ & $5(100)$ \\
LRP & $18(100)$ & $13(100)$ & $5(100)$ \\
MT & $9(50.0)$ & $6(46.2)$ & $3(60.0)$ \\
\hline
\end{tabular}


ealba, I.C. 2001. Metallothionein expression in canine and feline mammary and melanotic tumours. J. Comp. Pathol. 125: 130-136.

3. Dungworth, D.L., Hauser, B., Hahn, F.F., Wilson, D.W., Haenichen, T. and Harkema, J.R. 1999. Tumors of the Lung. pp. 2538. In: Histological Classification of Tumors of Respiratory System of Domestic Animals, 2nd Ser, The Armed Forces Institute of Pathology, Washington, D.C.

4. Dziegiel, P., Jeleń, M., Muszczyńska, B., Maciejczyk, A., Szulc, A., Podhorska-Okolów, M., Cegielski, M. and Zabel, M. 2004. Role of metallothionein expression in non-small cell lung carcinomas. Rocz. Akad. Med. Bialymst. 49: 43-45.

5. Fukushima, K., Okai, Y., Matsuura, S., Tsujimoto, H. and Endo, Y. 2006. Molecular cloning of feline lung resistancerelated protein (LRP) cDNA and its expression in a feline lymphoma cell line and adriamycin-resistant subline. J. Vet. Med. Sci. 68: 885-890.

6. German, U.A. 1996. P-glycoprotein- a mediator of multidrug resistance in tumor cells. Eur. J. Cancer 32: 927-944.

7. Grant, C. E., Valdimarsson, G., Hipfner, D. R., Almquist, K. C., Cole, S. P. and Deeley, R. G. 1994. Overexpression of multidrug resistance-associated protein (MRP) increases resistance to natural product drugs. Cancer Res. 54: 357-361.

8. Izquierdo, M.A., Scheffer, G.L., Flens, M.J., Shoemaker, R.H., Rome, L.H. and Scheper, R.J.1996. Relationship of LRPhuman major vault protein to in vitro and clinical resistance to anticancer drugs. Cytotechnology 19: 191-197.

9. Kelley, S.L., Basu, A., Teicher, B.A., Hacker, M.P., Hamer, D.H. and Lazo, J.S. 1988. Overexpression of metallothionein confers resistance to anticancer drugs. Science 241: 18131815.

10. Kitazono, M., Sumizawa, T., Takebayashi, Y., Chen, Z.S., Furukawa, T., Nagayama, S., Tani, A., Takao, S., Aikou, T. and Akiyama, S. 1999. Multidrug resistance conferred by the lung resistance-related protein (LRP) on human colon carcinoma SW-620 cells. J. Natl. Cancer Inst. 91: 1647-1653.

11. Kobayashi, K., Shimada, A., Yamano, Y. and Umemura, T. 1997. Molecular cloning of a canine metallothionein cDNA. $J$. Vet. Med. Sci. 59: 819-823.

12. Kumar, V., Cotran,R.S. and Robbins,S.L. 2004. Lung tumors. pp. 624-631. In: Robbins Basic Pathology, 7th ed, Saunders, Philadelphia, Pennsylvania.
13. Laack, E., Bokemeyer, C. and Hossfeld, D.K. 2008. Adjuvant chemotherapy after complete resection of non-small cell lung cancer. Dtsch. Arztebl. Int. 105: 249-254.

14. Matsumoto, Y., Oka, M., Sakamoto, A., Narasaki, F., Fukuda, M., Takatani, H., Terashi, K., Ikeda, K., Tsurutani, J., Nagashima, S., Soda, H. and Kohno, S. 1997. Enhanced expression of metallothionein in human non-small-cell lung carcinomas following chemotherapy. Anticancer Res. 17: 3777-3780.

15. Miyoshi, N., Tojo, E., Oishi, A., Fujiki, M., Misumi, K., Sakamoto, H., Kameyama, K., Shimizu, T. and Yasuda, N. 2002. Immunohistochemical detection of P-glycoprotein (PGP) and multidrug resistance-associated protein (MRP) in canine cutaneous mast cell tumors. J. Vet. Med. Sci. 64: 531-533.

16. Nooter, K. and Stoter, G. 1996. Molecular mechanisms of multidrug resistance in cancer chemotherapy. Pathol. Res. Pract. 192: $768-780$.

17. Paredes, L. A., Blanco, G.C., Echenique, E.M. and Lobo, C. 2007. Expression of proteins associated with multidrug resistance and resistance to chemotherapy in lung cancer. Arch. Bronconeumol. 43: 479-484.

18. Richard, W. N. and Guillermo,C. C. 2005. Lung tumors. pp. 317-319. In: Small Animal Internal Medicine, 3rd ed, Mosby, Missouri.

19. Sato, T., Ito, J., Shibuya, H., Asano, K. and Watari, T. 2005. Pulmonary adenosquamous carcinoma in a dog. J. Vet. Med. A. Physiol. Pathol. Clin. Med. 52: 510-513.

20. Sauna, Z.E., Smith, M.M., Müller, M., Kerr, K.M. and Ambudkar, S.V. 2001. The mechanism of action of multidrug-resistance-linked P-glycoprotein. J. Bioenerg. Biomember. 33: 481491.

21. Shimada, A., Yanagida, M. and Umemura, T. 1997. An immunohistochemical study on the tissue-specific localization of metallothionein in dogs. J. Comp. Pathol. 116: 1-11.

22. Sumizawa, T., Chuman, Y., Sakamoto, H., Iemura, K., Almquist, K. C., Deeley, R. G., Cole, S. P. and Akiyama, S. 1994. Non-P-glycoprotein-mediated multidrug-resistant human KB cells selected in medium containing adriamycin, cepharanthine, and mezerein. Somat. Cell Mol. Genet. 20: 423-435.

23. Wilson, D. W. and Dungworth, D. L. 2002. Tumors of the respiratory tract. pp 365-399. In: Tumors in Domestic Animals, 4th ed. (Meuten, D. J. ed.), Iowa State Press, Iowa. 